\title{
Urbana (2003) de Rodolfo Fogwill, o cómo revertir prácticas narrativas de la literatura de consumo
}

Urbana (2003), de Rodolfo Fogwill, continúa la cruzada personal del autor contra aquellas prácticas discursivas en conformidad con lo que Nelly Richard denomina el "signo mercantilizado". Es decir, contra la reapropiación semántica por parte de agentes socio-económicos y políticoculturales de espacios de significación previamente cargados de contenido socio-político y que ahora obedecerán a pautas mercadotécnicas. El enfoque de Urbana en el proceso escritural, el modo en que la novela contribuye a la reflexión sobre la creación literaria y desdeña la actual obsesión con el suceso, busca recuperar un diálogo entre texto y lector en gran parte interrumpido por las políticas de bestsellerización de cierta fracción de la industria editorial. Fogwill consigue así crear una narrativa contestataria a procesos de mercantilización literaria dictados por cierto sector del mercado editorial.

Creo que es mucho más importante pensar que contar, pero para imponer el arte de pensar hay que contar. La razón no se sostiene sin relatos.

Rodolfo Fogwill, Primera persona: conversaciones con quince narradores argentinos.

La profunda transformación de los espacios de producción, circulación y consumo de los bienes culturales en conexión con la radical reconfiguración sufrida por los imaginarios socio-culturales que ha experimentado la sociedad argentina en las últimas cuatro décadas responde, en primer lugar, al quiebre de los lazos sociales, agudizado por la última dictadura militar, y cuyo gesto represivo, en opinión de Oscar Landi, "fragmentaba el tejido social, privatizaba, generaba microculturas del miedo y donde el discurso oficial se orientaba a una ofensiva sobre la memoria colectiva, realimentadora de las identidades sociales y políticas del ciclo histórico que se intentaba cerrar" ("Cultura y política" 72). Dicho

REVISTA CANADIENSE DE ESTUDIOS HISPÁNICOS 40.2 (INVIERNO 2OI6) 
discurso oficial se desprendió de contenidos y signos de carácter cívicopolítico, adquiridos históricamente por gran parte de la población y que componían el imaginario socio-cultural, para incorporar un perfil social que estaría definido por su posición dentro de la sociedad de consumo, perfil promovido por la política cultural del Ministerio de Economía ("Cultura y política" 72). Esta operación de fragmentación social, de desarticulación de colectivos sociales y políticos, y la "penuria de sentido" que, en palabras de Landi, atravesó Argentina durante largos años como efecto de la represión imperante así como del plan socio-económico de corte neoliberal entonces implementado, tuvo como resultado un empobrecimiento de la vida cultural que resultó a su vez en una considerable disminución de la producción y de los consumos de bienes simbólicos ("Cultura y política" 73 ). ${ }^{\mathrm{I}}$

La creciente fragmentación y polarización social que tiene lugar durante los 70 y 80 en la sociedad argentina se vio, además, agudizada por la crisis económica del 2000 y 200I, cuyos cambios produjeron, según Ana Wortman, "un retroceso significativo en el sostenimiento de la cultura, aunque en el marco de un proceso contradictorio, donde por una parte disminuye el financiamiento público del sector, y por la otra se aumentaban las expectativas sobre la rentabilidad de la cultura, que pasa a ser concebida con mayor claridad como un renglón productivo que es parte de las cuentas nacionales" ("Consumos culturales" ${ }^{17}$ ). ${ }^{2}$ Wortman señala, a su vez, que serán las principales entidades crediticias internacionales las que insistirán sobre esta "potencialidad de la cultura en la generación de riqueza" y pasarán a "recom(endar) y abr(ir) líneas de financiamiento para solventar acciones en el área" ("Consumos culturales" 17). ${ }^{3}$ El acelerado potencial de rentabilidad de la cultura derivará, así, en una marcada transformación de unos contenidos en muchos casos supeditados a la presentación y difusión del producto cultural que, atravesado ahora por los campos del marketing y la publicidad, a través de las nuevas tecnologías de la comunicación, modificará tanto los espacios de circulación de la cultura como el sujeto que la consume. Los medios de comunicación, substitutos de espacios alternativos de representación durante la etapa dictatorial hasta llegar a convertirse en la actualidad en intermediarios de lo público, incluyendo de lo político, promoverán gran parte de los bienes culturales e interactuarán con el individuo a modo de "compensación de la pérdida de valor de los asuntos públicos" bajo el permanente marco de "debilitamiento de lo público y de (el) desencantamiento de la participación en sus asuntos" (Lewin 204). Hugo Lewin atribuye esta recomposición de los patrones de vida y del tejido social y, en particular, la reconfiguración de las relaciones entre medios de 
comunicación y los espacios de circulación de la cultura con el individuo, al hecho de que el yo "dej[e] de entenderse como esencia en sí - homo psicologicus - y pas[e] a pensarse como resultado de una interpelación múltiple, fruto de distintas construcciones y reconstrucciones" (I99). Zygmunt Bauman coincide en cómo dicho sujeto, ahora en su rol de consumidor de bienes, sufrirá un acelerado proceso de individualización en el cual deberá encontrar su propia manera de enfrentar los problemas creados socialmente (47). ${ }^{4}$ Será en este marco donde "diversas construcciones discursivas intentarán fomentar una seguridad ontológica, perdida a partir de microrrelatos de carácter más privado, y que vendrán a gozar de gran recepción cultural, como será el caso de películas, revistas, libros de autoayuda, best-sellers, informativos televisivos ... talk shows y reality shows" (Lewin 200). En directa conexión con los espacios de circulación en la era mediática, destaca el acelerado crecimiento de los estudios de mercado y el surgimiento de nuevos agentes culturales, un nuevo tipo de intelectual al que Wortman llama mediador, "más vinculado[s] a las nuevas formas de producción cultural asociadas a la industria cultural" ("Clases medias" 77). En el ámbito editorial, y como resultado de procesos de transnacionalización cultural que trae consigo la globalización económica sobre todo a partir de la segunda presidencia de Carlos Menem a finales de los 80, serán los consorcios o comités editoriales, encabezados por los agentes comerciales, los que pasarán a decidir qué libros saldrán a la luz en función de su atractivo literario dentro del mercado global (Saítta 25I).5 De ahí se sigue que las características de la oferta cultural han pasado a condicionar los estilos de apropiación y hasta parte de la interpretación que hace el público de los bienes culturales en cuestión (Landi, "La crisis" I), y que "el acceso a los bienes culturales (libros, teatro, cine) ha constituido un valor en la conformación de la subjetividad, la formación ciudadana" (Wortman, "Clases medias" 76). Estos, entre otros factores, han modificado el vínculo entre sociedad y cultura hasta llevar a una acelerada apropiación de lo cultural por la sociedad de consumo y, por lo tanto, a una marcada mercantilización cultural.

Entre los autores contemporáneos que más reiteradamente han ahondado, y con una mirada crítica más irreverente, en la relación entre mercado y literatura destaca sin lugar a dudas Rodolfo Enrique Fogwill (194-20IO). Su inicial interés, desde niño, por la semiotica derivó primero en una larga trayectoria profesional en los campos del marketing y la publicidad para más tarde dedicarse a la sociología y a su faceta de columnista en temas de políticas culturales, comunicación y literatura. ${ }^{6}$ Todo ello le permitió adquirir una mirada marcadamente inquisitiva desde 
la que, a menudo, analiza contenidos así como mecanismos lingüísticos y discursivos de producción en el ámbito de las políticas culturales y en el contexto de la posdictadura argentina, donde su relativamente tardía labor crítico-literaria estuvo marcada por posiciones ex-céntricas y contestatarias inevitablemente influidas por dicho bagaje. Entre las obras del autor que más incisivamente problematizan la mercantilización de los bienes culturales y la manipulación lingüística y discursiva llevada a cabo por lor agentes o mediadores culturales destaca En otro orden de cosas (2002). Dicha novela denuncia, por una parte, lo que Nelly Richard califica de "mercantilización de los signos", es decir, la reapropiación semántica por parte de agentes socio-económicos y político-culturales de espacios de significación previamente cargados de contenido socio-político y que ahora obedecen a pautas mercadotécnicas. ${ }^{7}$ Por medio de una profunda reflexión sobre los mecanismos discursivos empleados para construir políticas culturales, esta novela consigue exponer el gradual proceso de desarticulación del carácter crítico-político de las mismas. Pero, además, la obra va más allá al buscar resistir todo proceso de normativización lingüística y discursiva mediante un carácter autorreflexivo sobre el proceso de creación del mismo relato que es la novela. Es decir, se da en esta novela un constante proceso de (re)evaluación y reflexión discursiva, no sólo por parte del protagonista sobre las propuestas de políticas culturales que estudia sino también sobre su propio texto de memorias que se encuentra confeccionando. Este ejercicio de (re)construcción textual ocurre así en dos niveles distintos del relato y conduce a un autocuestionamiento de la propia autoridad discursiva del texto que es En otro orden de cosas.

Su siguiente novela, Urbana (2003), prosigue con la reflexión sobre las prácticas de producción y consumo cultural para alcanzar, esta vez, al mundo editorial y denunciar los efectos mercadotécnicos en el campo literario. De nuevo, predomina el tono metatextual que, aunque constante en la producción literaria de Fogwill, adquiere aquí un papel aún más preponderante, en cuanto que, tanto el sujeto de la enunciación como los enunciados tratan de desmarcarse constantemente de recientes tendencias literarias dictadas por el mercado editorial. Anterior, pues, a los principios crítico-literarios del autor, este enfoque en el ejercicio de creación textual y aquellos mecanismos lingüísticos y discursivos que lo constituyen - o bien lo amenazan por imposiciones externas de sentido han determinado y, en parte provocado, la actitud de irreverencia hacia el mundo editorial de la que hizo gala Fogwill en multitud de intervenciones públicas. ${ }^{8}$ Una actitud que, no hay que olvidar, forma parte de la propia imagen creada por el autor en su faceta de personaje público y que parte 
de la crítica interpreta como una "marca-Fogwill". 9 En este trabajo examinaré cómo la novela contribuye a la reflexión sobre la creación literaria, esta vez en lo referente al tratamiento de la estructura narrativa y también argumentaré acerca de los modos en que se busca recuperar un diálogo entre texto y lector, hoy día interrumpido por ciertas pautas literarias dictadas o promovidas por una parte del sector editorial. Con tal fin, me enfocaré en el estudio del carácter contestatario de las constantes intervenciones por parte del sujeto de la enunciación, reveladoras de la mirada-Fogwill.

Urbana viene enmarcada por un Prefacio que abre con la reflexión sobre la razón del título de la obra y luego sobre los contenidos y estructura de la misma, y donde finalmente queda expuesta la visión crítica del autor con respecto a los efectos del mercado y las leyes de compra-venta dentro del mundo editorial, así como la probable recepción que su novela encontrará. Parte de esta última reflexión aparece a continuación:

Idealmente (esta historia) debía eludir cualquier acontecimiento, pero en tal caso nadie la habría editado y no habría encontrado un lector. Rimando, puede afirmarse que los lectores acuden a la novela sedientos de acontecimientos. Algo ha de estar indicando esto: quizá haya tanta demanda de que en un texto sucedan cosas porque se descuenta que nada sucederá entre el texto y su lector. Pero los editores dominan el arte de administrar la medida justa que puede definirse como la presencia de un máximo de acontecimientos en el texto y ninguno por efectos de la lectura. Con ello consiguen que el lector termine de consumir manteniendo intactas sus cualidades más preciadas: su poder de compra y el hábito que lo llevara a pagar por algún nuevo título de esa colección. Idealmente, un día la industria terminará por librarse de los autores. Mientras tanto, se insiste en narrar como si nada estuviese ocurriendo. (7)

Fogwill denuncia aquí la obsesiva demanda actual de acontecimientos por parte de productores, distribuidores y consumidores de literatura. De dicho enfoque en el plano de la historia del relato se desprende que ya poco o nada ocurre entre texto y lector. Regresaré más tarde a dicha cuestión.

Esta demanda de acontecimientos es producto de una era mediática enfocada en proveer instancias de "realidad" dentro de un contexto cultural principalmente orientado a aunar entretenimiento y consumo. Dichas instancias contribuyen a la problemática inherente de la pantalla con respecto al desdibujamiento de la distinción entre realidad e imagen y, más aún si cabe, por aquella programación cultural que intenta aunar 
contenidos de naturaleza informativa con los de entretenimiento, lo que conduce muchas veces a una espectacularización del suceso.

El texto hace alusión a esta transformación de ciertos medios de comunicación informativos, antes regidos por un principio de veracidad que ahora, denuncia el narrador, están cediendo cada vez más espacio a contenidos espectacularizados y, como mínimo, pseudorreales: "Ahora nadie ignoraba que la prensa vivía pendiente de la televisión y que cada año era mayor el espacio que destinaba a informar lo que va sucediendo en canales y estudios. El animador estaba convencido de que con la cultura sucedería lo mismo que con los noticieros" (76-7). Dicha demanda es, a su vez, resultado del quiebre social que, como sabemos, tiene lugar durante la dictadura militar con la implementación del modelo neoliberal y donde ciertas construcciones discursivas, como los microrrelatos de carácter privado, intentarán devolver cierta seguridad ontológica a un individuo cuyo lazo con su colectivo se halla substancialmente debilitado (Lewin I99). Estas construcciones discursivas se verán traspasadas por un sentido de objetividad y verosimilitud que las tecnologías de la comunicación proyectan en su papel de proveedores de "realidad" y "verdad" pero que, regidas por pautas mercadotécnicas, provocarán no sólo un desplazamiento de nuestros propios criterios perceptuales y cognitivos, sino también la falsa percepción de una equivalencia entre pantalla y realidad que, a su vez, reorientará dispositivos de captación social hacia criterios despolitizados y supeditados a pautas de consumo. El efecto en lo literario se traducirá, según Paula Sibilia, en cómo "la ficción aparece amenazada desde dos ángulos. Desde adentro, se debilita la función rectora que la novela jugaba en la búsqueda interna del sujeto moderno, a partir de los cambios en su constitución y sensibilidad. Y desde afuera, por el desarrollo de la era de la información" (197). Dicha irrupción de lo real en y por los mass media, producto a su vez de la reconfiguración de imaginarios socioculturales y políticos, desembocará en la demanda de acontecimientos antes comentada y, por lo tanto, en lo que Sibilia considera una "crisis actual de la ficción tradicional y demanda de seguridad ontológica contemporánea en conexión con nuevas narrativas de base no ficcional" (207). Este fragmento del Prefacio revela, pues, un profundo sentido de crítica hacia el mercado editorial por haberse dejado arrastrar, en su mayor parte, por políticas de consumo implementadas por los aparatos massmediáticos y que ahora contagiarán a la industria editorial literaria. ${ }^{\mathrm{O}}$

La mirada crítica de Fogwill no se detiene en el Prefacio, sino que pasará, en el relato que le sucede, a entablar diálogo con aquello sobre lo que ha reflexionado previamente. Tan pronto como nos adentramos en el 
texto principal de Urbana empezamos a ver el alto grado de intertextualidad, de negociación de significado, que el Prefacio y el relato mantienen entre sí. En un principio, llama la atención el carácter autorreferencial del texto, con diversas alusiones a, por ejemplo, el cuerpo sin vida de lo que parece un escritor frustrado que yace junto a su "Libro Acariciado" (Io) de I43 páginas, casualmente, o no, el mismo número de páginas de la novela de Fogwill. ${ }^{\mathrm{II}}$ El texto se abre así con la noticia de un fallecimiento y con la aparición de un ejemplar de novela entre las pertenencias del muerto. Lo curioso es que pronto descubrimos que el relato al que se hace alusión en el Prefacio, y que deducimos es Urbana, alude también al relato contenido en el libro escrito por el personaje fallecido al principio de la novela. Así, el autor va dejando su huella no ficcional dentro de la ficción. Pero el juego metatextual de Urbana va mucho más allá de la autorreferencialidad: si el Prefacio parecía introducir el relato principal observando cómo "ésta era una historia de personajes sin cara y terminó como un relato de personajes sin caras ni nombres" (7), este relato explica, a propósito del texto escrito por el personaje difunto, cómo

el libro no daba nombres, y algunas cosas que decía de gente o de casas no permitía formarse una idea respecto de a quiénes o a qué barrios se refería. Al parecer, todo lo que contaba había ocurrido en la capital, en Buenos Aires, y de algo estaba seguro: en lo que leyó ... salvo algunos presidentes de la Argentina y militares del tiempo de las escarapelas, no aparecía el nombre de ninguna persona (23).

El narrador, al referirse a la ausencia de nombres de los personajes y de datos concretos, nos remite a la presentación que hace el autor de su novela. Es decir, dicha descripción del contenido de la novela se aplica también al contenido de Urbana. Por lo tanto, vemos cómo las reflexiones del Prefacio dialogan con el texto de la novela en distintos niveles narrativos. Esto no solo dota al texto de un carácter metatextual, sino que sugiere que la metatextualidad es, de hecho, la técnica a la vez que el enfoque principal de la novela de Fogwill. Las constantes reflexiones sobre el proceso y técnica de escribir y, más en concreto, del acto de creación literaria, suponen el acto último de resistencia ante las pautas editoriales previamente criticadas en el Prefacio.

El Prefacio cumple así con el fin último que según Gérard Genette detenta todo texto que enmarca al texto principal, todo paratexto, el de constituir "a zone not only of transition but also of transaction" (2). En este sentido, el paratexto que es el Prefacio poseería aquí una función mediadora con el texto principal para, en última instancia, dotar al lector 
de una conciencia de su rol actante en el proceso de negociación de significados implícito en este acto de lectura. De esta manera es como interpreto la reivindicación de Fogwill de que algo suceda "entre el texto y su lector": El hecho de que el texto busque o promueva entablar una comunicación conducente a procesos cognitivos en los cuales tenga lugar una transacción y negociación de sentido con el lector y que sí conducirían a lo que el autor considera un suceso real. Con este fin, y a pesar de que el autor admite incorporar acontecimientos en su obra para poder encontrar un público y una vía de publicación, un vehículo editorial, parece que el texto de la novela trata de resistir a los acontecimientos manteniendo mínimamente el hilo de las distintas historias entretejidas. Así, el relato central, que versa sobre la fiesta de inauguración de un edificio, el Karina, en una zona residencial, se abre a otros secundarios, y donde todos o muchos de estos relatos conforman el pretexto perfecto para que el narrador a menudo se desvíe a lo que en un principio constituyen comentarios o descripciones de sucesos triviales que desembocan en digresiones de carácter metaliterario sobre distintas cuestiones en torno a procesos de creación literaria. Así, por ejemplo, el comentario aparentemente banal sobre unos insectos que revolotean alrededor del libro del difunto da pie a la reflexión sobre lo que parece ser una mirada crítica y mordaz al modo en que la preponderancia otorgada a la construcción de la trama tiende a arrastrar al resto de elementos que componen el relato:

Saltó otra cotorrita agregándose a esa mayoría de insectos que nunca nadie aplastará: otro objeto perdido entre los hilos del relato que se libra a su propio curso con la esperanza de volver a recogerlo en un haz y destejerlo recuperando fibra a fibra la trama que volverá a torcer y a retejer hasta tensar la cuerda narrativa, los hilos del relato, el curso de las tramas curvándose bajo el peso de su mero transcurrir, lo atribuible, la red de las metáforas, el encordado de la prosa, la tensión del clavijero sintáctico, la resonancia de la caja hueca de las ideas, la estupidez con todo lo que su armonía infinita puede llegar a contener, y la afinación del instrumento narrativo, y el breve texto, y los textículos y la chotez de los textos de prensa. ( $17-8)$

Enfatizando la condición inherentemente artificial de construcción lingüística y discursiva de todo texto, y por tanto el cierto grado de manipulación narrativa que presenta, las reflexiones a menudo sarcásticas sobre el proceso escritural y creativo se repiten a lo largo de la novela entrelazándose, superponiéndose, en ocasiones a las historias. Así ocurre con la reflexión del narrador al inicio del cuarto capítulo sobre lo que 
acaba de contar al final del capítulo anterior: "A veces conviene ponerle pecas en la mejilla a un personaje y sugerir un vínculo entre pez, peca, pescar y un pecado, sólo para que el texto encuadre mejor o cierre justo en el límite inferior de la página" (46). En un principio, se trata de comentarios que parecen simples guiños al lector para que se detenga y distancie del enfoque en la acción, como en el siguiente ejemplo: "En un relato la digresión es un cambio territorial que desconcierta al gregario lector..." (6I). Pero, en la mayoría de los casos, dichas digresiones tienen como objeto despertar en el lector un nivel de conciencia más profundo sobre la naturaleza del texto y los diferentes elementos que lo componen. Así ocurre a su vez con la reflexión que en relación a la naturaleza y rol jugado por personajes, narrador, autor y lector tiene lugar al comienzo del quinto capítulo, y que desemboca en la aceptación, por parte del narrador, de la futilidad de dar con las palabras justas que transmitan el sentido justo al lector (62).

Este tipo de reflexiones cobra un carácter aún más metaficcional cuando confluyen en sentido y técnica con el relato, o bien, cuando el narrador pasa a incorporar algún aspecto, elemento, o técnica sobre los que previamente reflexionó y que, incluso en ocasiones, mencionó querer implementar, o bien comentó el impacto de su implementación, con el fin de hacer más obvia para el lector esta manipulación a nivel estructural y discursivo a la vez que de contenido: "Otras veces se impone determinar la hora. A las doce quedaron a cargo del vestuario, las mismas promotoras..." (46). Es decir, el texto de la novela pasará a convertirse en el laboratorio donde el narrador-autor expondrá las limitaciones y el carácter subjetivo inherentes a todo acto de construcción textual y, más específicamente, del relato. Con respecto a dicha construcción narrativa, el narrador contrapone, a continuación, el desorden natural de las pequeñas historias que la componen al carácter orgánico del acontecer histórico, al modo en que los autores, $y$, en particular, aquellos autores que se dejan arrastrar por las pautas mercadotécnicas actuales y moldean sus relatos hasta obtener un producto que contenga aquellos ingredientes pseudoliterarios que agradan al consumidor:

La Historia arrastra infinitas historias microscópicas sin atender a nada y sin pretender nada de sus desenlaces. A su manera, acontece la Historia. Pero no es un relato y a pesar de tanto esfuerzo humano, sigue ahí, imponiéndose sin contar nada y sin contar con nada. Y sin fábula ni moraleja alguna, salvo ese "nada que decir" que su silencio siempre está proclamando. (II5) 
El narrador-autor no sólo pone de manifiesto nuevamente su admiración por el transcurrir libre y sin ataduras que constituye la esencia de la Historia, sino que se esfuerza por dejarse llevar por un proceso de creación textual en cierto sentido desligado de fórmulas narrativas de representación y, especialmente, desentendiéndose de aquellas que desemboquen en fábulas o moralejas en el mismo texto de Urbana. En este sentido, el dejar fuera del texto información y elementos como la cuidada caracterización de sus personajes, que para la narrativa más popular resultan fundamentales en la comprensión última de la trama, responde aquí a una necesidad por resistir aquella mirada completa, totalizante, de la ficción más convencional. De aquella narrativa en la cual nada queda omitido, se despejan todas las dudas, y se impone una dirección que, además, no deja espacio para la espontaneidad, en contraste con el devenir orgánico de los sucesos que conforman la realidad: "Bajo la apariencia de tender a un destino, el relato pretende - o requiere - dar con esas situaciones donde lo que normalmente habría que mantener en reserva se manifieste" (I2O). El narrador es consciente aquí de esa codependencia del autor para con su público, de la necesidad de moldear el discurso de su mensaje, su relato en este caso, para que el lector pueda decodificarlo. Este moldeamiento supone imponer un sentido y una estructura que, para el autor, equivalen a ejercer una violencia de sentido sobre el texto. Tal y como observa Juan Ignacio Boido, el problema de Fogwill "no era pensar, sino saber, ser consciente, de que toda verdad necesita ser contada de determinada manera para ser entendida" (2). Señalé antes que Urbana intenta, quizás consigue, desligarse en cierto grado de los mecanismos de discursivización porque, como ya ha argumentado Francisco Solano, la obra "se resuelve de este modo en un compendio, podríamos decir, de impotencia literaria ... de insumisión que no se libra de la dominación contra la que se rebela" (49). En dicha reseña crítica sobre Urbana y sobre el quehacer literario de Fogwill falta reconocer sin embargo que el autor, en su faceta de agente de marketing y publicidad, dedicó varias décadas de su vida y trayectoria profesional a crear trampas lingüísticas y discursivas que atrajeran a un público consumidor y que esta conciencia de la manipulación formal, ejercida en dichos campos, lo acompaña obsesivamente a lo largo de toda su carrera literaria, y de hecho, constituye el eje central de sus divagaciones literarias. Tal y como observa Boido: "Fogwill sabe que combate, se bate a duelo, embosca, secuestra y confronta con las mismas armas que las de sus enemigos: no sólo las palabras, sino los saberes que las manipulan, los discursos que las pervierten" (2). Quizás la más violenta de las hegemonías de sentido sea la que el mismo Fogwill denomina "herencia semántica del proceso" en su 
ensayo "La Guerra sucia: un negocio limpio de la industria editorial", y que describe como "ese léxico falso cuya mera enunciación supone un acuerdo de fondo sobre las reglas del juego ... Con imágenes, con contratos terminológicos, el orden social 'se hace entender' mejor que con la enunciación de cualquier decálogo de moral pública" (Los libros 83). Todas estas "violencias discursivas", tanto las malversaciones semánticas, producto de viejas o nuevas políticas culturales impuestas por los poderes dominantes, como aquéllas que resultan de la condición intrínsecamente artificial y constrictiva del lenguaje y que, básicamente, constriñen y delimitan todo proceso cognitivo, al menos en el momento de ser articulado, han inspirado una actitud de resistencia en la narrativa de Fogwill, que no por ello se sabe menos derrotada desde antes de iniciarse el proceso creativo. Sin embargo, y disintiendo con Francisco Solano con respecto a que Fogwill acaba desviándose "en favor del lector convencional mediante fragmentos de historias y sucesos poco menos que triviales" (49), Urbana consigue, en mi opinión, trascender con éxito convencionalidades con respecto a construcción de trama y caracterización de personajes, puesto que ninguna de las minihistorias que conforman el macrorrelato se resuelve en cuanto a sus respectivos argumentos se refiere. Al contrario, todas ellas terminan siendo meros accidentes narrativos cuyo principal propósito es el de propiciar digresiones sobre la naturaleza del relato y su complejo proceso de creación, lo cual confirma que la metatextualidad constituye tanto la técnica como el enfoque de contenido principal de la novela.

Como hemos visto, las historias que componen Urbana se encuentran supeditadas a lo que realmente constituye el eje central del texto: la reflexión que sobre su propio ejercicio creativo y escritural lleva a cabo el narrador a través de sus continuas intervenciones, reflexiones que se mantienen en permanente diálogo con lo declarado por el narrador-autor en el Prefacio. El elemento metatextual que integra dicha reflexión no sólo se convierte aquí en herramienta de trabajo sino que, al cobrar un completo protagonismo, más aún si cabe a la luz de la crítica expuesta en el Prefacio, se confirma como la cuestión central de la novela. Y es que dicha metatextualidad opera como mecanismo discursivo de resistencia a aquel desdén de la industria editorial reciente por que algo pase entre texto y lector y que Fogwill denuncia al comienzo de su obra. Las continuas muestras de autorreferencialidad y metatextualidad que se producen en el texto a partir de constantes digresiones así como de despliegues de estrategias discursivas que se aplican al mismo texto de la novela, luego de haberlas comentado previamente, reproducen el proceso de creación de un relato dentro de Urbana, forzando al lector a activar dispositivos de 
lectura crítica. De esta manera, el texto entabla un diálogo continuo con un lector que debe permanecer alerta si es que quiere llegar a discernir el propósito del texto. El acontecimiento que, según el autor, constituye objeto de obsesiva demanda al nivel de la historia por parte de productores y consumidores de literatura, el evento, pasa aquí al plano discursivo (mientras que al nivel de la historia pasa a un segundo plano) para provocar, primero, una lectura activa, una transacción de significados entre texto y lector, y segundo, la reflexión sobre la naturaleza de la narrativa. El resultado es la activación de una conciencia muchos más inquisitiva y crítica en un lector que, se pretende, nade a contracorriente de unas pautas literarias marcadas por el mercado editorial en el que predominan aquellos textos que no buscan ni promueven entablar una comunicación conducente a una transacción y negociación de sentido con el lector, a procesos de lectura activa que sí conducirían a lo que el autor considera un suceso real. Es así como el autor intenta contestar y revertir patrones literarios y editoriales actuales. Patrones contra los que, por otra parte, el Fogwill-personaje público ha arremetido en infinidad de ocasiones y donde ha preferido crear y jugar con su propia imagen pública hasta convertirla en la ya mencionada marca-Fogwill, antes que entrar en una relación de dependencia de los productores culturales. Tal y como explica Gabriel Vommaro: "[E]n Fogwill no había un desprecio por la celebridad de escritor, que él buscó con las armas legítimas del provocador, sino por la situación de dependencia respecto de los mecanismos de producción de esa celebridad" (cit. en Cristófalo I2I). En una encuesta realizada en 1982 en la revista Vigencia, Fogwill respondía a la pregunta “¿Qué espera el editor del escritor?”:

[L]os editores reclaman que el autor pose para sus presentaciones, que haga "chivos" de sus autores y solapas de sus títulos más débiles, que se constituya como estrellita y pose para los medios masivos más embrutecedores y que trate como a sus pares al sinnúmero de "hombres de letras" que pululan como asesores o encargados de prensa de las gerencias. Particularmente, los editores exigen que se pague con promesas de éxito, pero como ahora son pocos los autores que pueden aportar un público comprador fiel, reclaman que los autores muestren buena predisposición para el ejercicio de todas las gestiones que requiere la obtención de ventas. (Los libros 277-78)

Si Fogwill denunciaba aquí el protagonismo otorgado al envasado del producto cultural, al show al que los autores se ven a menudo arrojados por sus casas editoriales, dicha denuncia, formulada ya en tiempos de dictadura, resuena con más fuerza en Urbana tras veinte años de 
incremento exponencial de la hegemonía del mercado global. De hecho, entre las múltiples alusiones y críticas mordaces al poder ostentado por los mass media y el mundo de la publicidad, encontramos en la novela la denuncia del protagonismo otorgado a los espacios de circulación de bienes culturales y la conciencia de cómo éstos han empezado a reemplazar a los mismos bienes: "Con el tiempo, pensaba, toda la cultura se reduciría a los programas culturales de cable, y lo que no aparezca en esos espacios podrá existir igual que siempre pero no será algo que suceda en la cultura" (76). En el ámbito de lo literario, este énfasis en el plano de la representación, en detrimento de lo representado, invita al potencial consumidor a mirar hacia afuera del texto, a enfocarse en el envase y no tanto en su contenido. El resultado es una reorientación de la mirada del lector-consumidor hacia criterios menos analíticos, lo cual repercutirá en la manera en que aborda el texto así como en el acto de lectura. Dicho acto de lectura se verá condicionado por todos aquellos discursos o dispositivos de sentido que presentan el texto, bien a través de actos promocionales de venta, bien a través de contenidos en paratextos como el de la contraportada que, cada vez con mayor asiduidad, vienen introducidos por colegas de profesión de mayor tirada y que, muchas veces empujados por el agente editorial de rigor, se enfocan en enfatizar el grado de satisfacción que el lector encontrará en el consumo de dicha obra. Este énfasis en los significantes por encima de los significados, en los espacios de circulación de bienes más que en los bienes en cuestión, asegura una continuidad de consumo, una fidelidad entre consumidor y mercado. De ahí que, en opinión de Fogwill, el enemigo de la narrativa sea

la falta de imaginación, la chatura, la convención, el marketing editorial, el servilismo y las ideas preenvasadas que los distintos grupos políticos proponen al que escribe. La militancia para el narrador consiste en resistir sus presiones y seducciones, combatiéndolas con el arma que más eficaz se ha revelado en este frente: la buena escritura. (Los libros 279)

Buena escritura, entendida así por el autor por cuanto que no sólo intenta articular y compartir una conciencia de sus limitaciones, de unos mecanismos lingüísticos y discursivos que la acompañan desde su incepción, sino que consigue relativamente boicotear al tiempo que desprenderse de ciertos mecanismos de sentido hegemónicos imperantes en la actualidad. Retomando la idea que sirvió de epígrafe introductorio a este trabajo, según Fogwill "para imponer el arte de pensar hay que contar. La razón no se sostiene sin relatos" (cit. en Speranza 5I). Urbana ejemplifica, en mi opinión, el papel crítico jugado por cierta narrativa a la 
hora de (re)pensar la naturaleza y los factores que influyen hoy día en la producción y diseminación de los bienes culturales. En un marco donde, tal y como advierte Ana Wortman, "la creatividad pierde autonomía, es absorbida por la dinámica capitalista. Está asociada al marketing y a la publicidad. Aunque como modelo cultural también es recuperada por la lucha y el conflicto social, absorbiendo valores políticos de crítica a una vida consumista y mercantilizada", la socióloga se pregunta si es posible preservar espacios de creatividad e imaginación liberadora en el contexto de la mercantilización de la vida social y cultural (85). La respuesta se halla, según Wortman, en promover "espacios culturales abiertos, públicos, gratuitos, basados en el valor de igualdad, que se contrapon(gan) ahora a espacios culturales privatizados" ("Clases medias" 80 ). ${ }^{\mathrm{I}}$

\section{College of Charleston}

\section{NOTAS}

I Landi añadía, en tiempos de transición, que "la larga crisis política, reflejada en la inestabilidad institucional, ha producido sus efectos desarticuladores en el campo cultural impidiendo la continuidad y consolidación de líneas estéticas, el procesamiento de controversias y de corrientes de pensamiento, el fortalecimiento de sus instituciones, la inestabilidad laboral de los trabajadores de la cultura, etc" ("Cultura y política" 70).

2 Con respecto a los emergentes estudios de mercado y su impacto en la industria cultural, Wortman explica cómo "la profundización de los procesos de desregulación estatal y privatización, (esto) se relaciona con la emergencia de consultoras privadas que realizan encuestas ... en función de la demanda de asociaciones y cámaras empresariales de los distintos sectores culturales involucrados" ("Consumos culturales" I5-16).

3 Wortman añade que "en contraste con planteamientos anteriores, el Banco Interamericano de Desarrollo (BID), el Banco Mundial (BM) y el Fondo Monetario Internacional (FMI) sostienen que 'la cultura cuenta', forma parte de las cuentas públicas y debe ser atendida en consecuencia (Sosnowski, 1999). En la Argentina, como se anotó, ya desde los años noventa era visible la profundización en los procesos de mercantilización o marketización de la cultura, donde los niveles del Estado catalizan la intervención del sector privado en áreas rentables, y conservan en su ámbito las áreas emblemáticas y no lucrativas, aunque procurando obtener rentabilidad de las mismas como condición para mantenerlas en funcionamiento. La recurrencia al patrocinio, la presencia de funcionarios que a la vez son conocidos productores culturales, la 
nueva atención prestada a las industrias culturales, las alianzas con el capital empresarial y financiero, dan cuenta de este cambio" ("Consumos culturales"

I7).

4 Bauman indica cómo "eliminada la perspectiva de llevar a cabo una revisión fundamental del orden social, ... la interpretación 'cultural' omite en silencio el hecho de que la desigualdad social es un fenómeno que se retroalimenta, y que uno de los principales factores de su consolidación consiste en representar las múltiples divisiones sociales nacidas de la desigualdad como productos inevitables de la libre elección, en lugar de verlas como una barrera problemática que impide la libre elección" (45).

5 Pero Saítta señala también cómo, hacia mediados de los 90, "se afianzan las editoriales independientes, un espacio alter-nativo para aquella narrativa que no se adecúa a las exigencias del mercado. Son editoriales de infraestructura pequeña, cuyo catálogo está compuesto por títulos de tirade mediana o minima ... Ciertos géneros narrativos o primeras novelas de escritores inéditos encuentran entonces su lugar en Beatriz Viterbo Editora, Simurg, Adriana Hidalgo, Tierra Firme, Paradiso o Alción" (255).

6 En la entrevista de Danilo Alberó-Vergara titulada "Nuestro espacio literario varía con accidentes como el viento", Fogwill explica cómo su labor de semiotista es muy anterior a la de publicista, "desde chiquito ... Yo siempre tuve mucha sensibilidad a los efectos connotativos de los sistemas de marcas, pero mucho antes de la publicidad. Yo llegué a la publicidad muy tarde, casi diez años después de haber trabajado en marketing, en desarrollo de marcas. De cualquier manera, esa sensibilidad es muy anterior" (Los libros 293).

7 En referencia al caso chileno, pero igualmente aplicable al argentino, Nelly Richard plantea cómo "los saberes tecnificados de la política, de la economía y de buena parte de la sociología chilenas respondieron con eficacia a la instrumentalización del mercado y del consenso que perfeccionó el dispositivo transicional, confeccionando lógicas ejecutivas que hablaran el mismo idioma (funcionario y numerario) que forjó la pragmática entre redemocratización y neoliberalismo" (9).

8 El primero de muchos otros desplantes al mundillo literario y en especial al editorial tendría lugar en I980, cuando Fogwill gana el recientemente inaugurado premio Coca Cola a las Artes y las Letras por su libro de cuentos Mis muertos punk (1979). Al negarse la Editorial Sudamericana, y también la empresa patrocinadora, a remover de la futura tapa del libro el sello de "Coca Cola”, Fogwill decide rechazar el premio y publicar el libro por su cuenta. El autor fundó su propia editorial, Tierra Baldía, en 1979, bajo la que publicó a poetas como Osvaldo Lamborghini y Néstor Perlongher, entre otros y también su primer libro de poemas El efecto de realidad (i979). 
9 Críticos como Américo Cristófalo se han aventurado a hablar de la "marca política Fogwill" (o "la política marca Fogwill”) que afirma es reconocible desde sus principios literarios (I4).

IO En crisis desde la década del 70, a partir de los 90 "la industria del libro experimentó un crecimiento en términos estadísticos, que no corresponde con una efectiva recuperación de la circulación y edición del libro de autor argentino" (Botto cit. en Wortman, "Consumos" 565). Para José Luis de Diego, dicha desnacionalización del mercado literario corre paralela a la desnacionalización de la industria editorial y a un "proceso de concentración del mercado editorial en pocos grupos" a partir sobre todo de los 90 (aunque también proliferaron numerosos emprendimientos editoriales pequeños), unido a la desnacionalización de la industria editorial e influencia de los grandes medios; los editores originarios son a menudo reemplazados por "técnicos financieros, contadores, o expertos en marketing que buscan una rentabilidad mayor y más acelerada" (53; 56). De Diego apunta cómo "hace ya varios años, la literatura comercial y la literatura de vanguardia tenían circuitos diferenciados y editoriales especializadas en cada caso; hoy se ha impuesto un criterio midcult en el que el best-seller de calidad convive con el best-seller abiertamente comercial, con el long-seller y con el texto experimental ... Ocurre que muchos de estos conglomerados multinacionales vieron crecer sus capitales en actividades que pueden ser muy respetables (negocios inmobiliarios, cadenas de televisión, y otras probablemente no tan respetables) e ingresaron en la industria del libro como una inversión más, de modo que si el editor era una especie de Jano Bifronte que miraba con una cara la cultura y con otra el dinero, ahora, como esas estatuas carcomidas por la intemperie, una cara se les ha borrado" (56-7).

II También hay una posible alusión a su novela más conocida, Los Pichiciegos, en Urbana: "La crónica guerrillera fue virtualmente un éxito ... todo gracias a que fue comentada en las secciones de política y actualidad y a pesar de que la mayoría de críticas eran hostiles, se ensañaban con unas pocas inexactitudes y lo calificaban de best seller oportunista" (77).

I2 Oscar Landi concuerda con Wortman y deja de manifiesto la urgencia de traspasar responsabilidades en cuanto a la creación y promulgación de espacios culturales públicos a organismos institucionales en los sectores educativo y de políticas culturales: "Para algunos especialistas, las políticas culturales deben tener su centro de gravedad no en el espectáculo masivo urbano, sino en la tarea cotidiana, participativa y menos visibles, de los centros culturales del barrio, de las iniciativas estéticas experimentales y de actividades en sintonía con el Sistema educativo ... La educación y las culturas públicas adquieren más importancia en medio de la debilidad de sentido de la palabra política y la erosión de los lazos sociales, entonces la creación y el 
consumo cultural refuerzan su papel de siempre en la elaboración que pueden hacer las personas, pese a todo, de la calidad de sus mundos de vida" ("La crisis" I).

OBRAS CITADAS

B AUMAN, ZYGMUNT. La cultura en el mundo de la modernidad líquida. México D.F.: Fondo de Cultura Económica, 2013.

B O ID 0, JUAN IGNACIO. "Inteligentes somos todos: Fogwill y los servicios de la inteligencia." Blog eterna cadencia 25 sept. 2013. S. pag. Web.

CRIST Ó FALO, A MÉRICo, E T Al. Fogwill: Literatura de provocación. Buenos Aires:

Universidad Nacional de General Sarmiento, 20II.

DE DIEGo, JOSE LUIS. "Un itinerario crítico sobre el mercado editorial de literatura en Argentina”. Iberoamericana I0. 40 (2009): 47-62.

ECHEVERría, ignacio. "Un narrador materialista: Rodolfo Enrique Fogwill." El País 8 marzo 2003. S. pag. Web.

F O GWIL L, RO D L L O E. Los libros de la guerra. Buenos Aires: Mansalva, 2008.

-. Urbana. Barcelona: Mondadori, 2003.

-. En otro orden de cosas. Barcelona: Mondadori, 200I.

GENETTE, GÉ RARD. Paratexts: Thresholds of Interpretation. New York: Cambridge UP, 1997 .

LAND I, OSCAR. "La crisis y el consumo cultural”. Clarín 24 junio 200 I. S. pag. Web.

—. "Cultura y política en la transición a la democracia". Nueva Sociedad 73 (1984): $65-78$.

LEW IN, HuGo. "Gran Hermano y la televisión que ve(re)mos: un lugar desde donde observar cambios socioculturales recientes" Las tramas del presente desde la perspectiva de la sociología de la cultura. Eds. Mario Margulis, Marcelo Urresti, Hugo Lewin et al. Buenos Aires: Biblos, 2011. I89-210.

RICHARD, NELly. Introducción. Pensar en/la postdictadura. Eds. Nelly Richard y Alberto Moreiras. Santiago de Chile: Editorial Cuarto Propio, 200I. 9-2O.

SAFERStein, EZEquiel andrés. "La Feria del Libro en Buenos Aires y la concentración del espacio editorial. Una aproximación a la sociedad del espectáculo en la circulación de libros". Kairos 17.32 (2013): 1-18.

SAít TA, SYLViA. "La narrativa argentina, entre la innovación y el mercado (I9832003)". La historia reciente. Argentina en democracia. Eds. Marcos Novaro y Vicente Palermo. Buenos Aires: Edhasa, 2004. 239-256.

Sibilia, PAUla. La intimidad como espectáculo. Buenos Aires: Fondo de Cultura Económica, 2008. 
S O LAN O, FRA NC IS co. "Idealmente, un escritor insumiso". Revista de Libros 8I (2OO3): 49 .

S PERANZA, GRACIELA. Primera persona: conversaciones con quince narradores argentinos. Buenos Aires: Norma, 1995. 37-5I.

W O R T M A N, ANA. "Globalización cultural, consumos y exclusión social”. Nueva Sociedad 175 (200I): $134^{-42}$.

—. "Clases medias y consumos culturales en la Argentina post años noventa." Entre la política y la gestión de la cultura y el arte. Nuevos actores en la Argentina contemporánea. Ed. Ana Wortman. Buenos Aires: Eudeba, 2003. 7389.

Wortman, ana y RUBens bayardo. “Consumos culturales en América Latina. Balances y desafios". Alteridades 22.44 (2OI2): II-2I. 